\title{
Novos Paradigmas na Prática do Psicólogo Escolar
}

\author{
Edla Grisard Caldeira de Andrada \\ Universidade Federal de Santa Catarina
}

\begin{abstract}
Resumo
Este trabalho reflete acerca das implicações paradigmáticas envolvidas na prática do Psicólogo Escolar nos dias de hoje, que tem sido modificada radicalmente ao longo de sua história voltando-se para uma prática relacional, baseada em um pressuposto do ser humano em construção histórica e social. Entretanto, quando este profissional adentra uma instituição educacional, depara-se com inúmeras dificuldades: falta de compreensão de outros profissionais da educação acerca do papel do psicólogo na escola; manutenção de uma prática excludente, individualista (o problema está no aluno ou na sua família), caracterizando um pensamento cartesiano e linear de causalidade. Porém, confrontando posturas, poderá criar espaços de reflexão junto aos sujeitos da escola, visando criar condições mais justas de existência. A partir do pressuposto histórico-cultural e da teoria sistêmica, apresentam-se formas de criação destes espaços de reflexão acerca dos problemas da escola, cujos resultados apontam para uma nova prática do profissional de psicologia escolar.

Palavras-chave: Psicologia escolar; teoria sistêmica; psicologia histórico-cultural.
\end{abstract}

\section{New Paradigms on the School Psychologist's Practice}

\begin{abstract}
This article is a reflection on the paradigmatic implications involved on the practice of the school psychologist, which has been modified towards a relational practice, based on the presupposition of the historical social constitution of the human being. However, when this professional works in an educational institution faces several difficulties, such as: lack of comprehension from the other professional of the school board about the role of the psychologist at school; maintenance of a excluding and individualist practice (the problem is in the mind of the student or in his family), characterizing a linear and Cartesian thought. However, confronting practices, the school psychologist may create situations in order to think together with school board on better and fair existing conditions. Based on the presuppositions of the culturalhistorical psychologist as well as the systemic theory, new forms of creation of these situations are presented and the results point to a new practice of the school psychologist.

Keywords: Educational psychology; systemic theory; cultural-historical psychologist.
\end{abstract}

Apesar de a Associação Brasileira de Psicologia Escolar/ Educacional (ABRAPEE: www.abrapee.com.br) considerar como Psicólogo Escolar aquele cuja atuação se caracteriza mais pela intervenşão na prática, enquanto que a dos psicólogos educacionais, geralmente, se direciona para as áreas de ensino e pesquisat, considero impossível o trabalho do Psicólogo Escolar, sem esse olhar do pesquisador, que observa, analisa, avalia e escreve novas possibilidades de atuação, principalmente quando observamos a atual conjuntura da Psicologia Escola/Educacional no país, onde ainda se busca sua identidade a nível curricular e principalmente na sua prática institucional. Por isso, utilizarei neste artigo o termo Psicólogo Educacional para todo e qualquer especialista que atue no âmbito educacional, especialmente o de ensino regular público.

Convém lembrar que as especialidades do profissional de Psicologia foram regulamentadas segundo a Resolução do Conselho Federal de Psicologia n ${ }^{\circ}$ 014/00, que pontuou as especialidades configuradas como as mais definidas no atual contexto sócio-político do país. Segundo artigo publicado no site do CFP (www.psicologiaonline.com.br): as definiçöes das especialidades foram baseadas no CBO (Catálogo Brasileiro de Ocupacoóes do Ministério do Trabalho)

\footnotetext{
${ }^{1}$ Endereço para correspondência: Largo Benjamin Constant, 691, 403, 88015390 , Florianópolis, SC.E-mail:edla@floripa.com.br

${ }^{2}$ A ABRAPEE entende por psicólogos escolares e educacionais aqueles profissionais que, devido a sua preparação universitária em psicologia e experiências subseqüentes nas áreas escolar e/ou educacional, trabalham para melhorar o processo ensinoaprendizagem no seu aspecto global (cognitivo, emocional, social e motor), através de serviços oferecidos a indivíduos, grupos, famílias e organizações.
}

$e$ apresentadas às entidades nacionais que representam os profissionais da área, para revisão e reformulação.

Dentre as especialidades, encontramos a do Psicólogo Escolar/ Educacional, cuja atuação deve estar no âmbito da educaşão formal realizando pesquisas, diagnóstico e intervenșão preventiva ou corretiva em grupo e individualmente. Envolve, em sua análise e intervencão, todos os segmentos do sistema educacional que participam do processo de ensino- aprendizagem.

Dessa forma, entendendo o trabalho do Psicólogo Educacional como acima descrito, este artigo contempla os paradigmas em voga quando se trata desta especialidade ao longo da história em nosso Brasil, assim como sua conseqüente prática. Também são contempladas as dificuldades atuais do Psicólogo Educacional que se encontra atuando em Escolas da Rede Pública Municipal e que nelas busca firmar a identidade desta especialidade.

\section{Um pouco de história}

É evidente que diante da sua especificidade, ou seja, a de envolver todos os segmentos do sistema educacional que participam do processo de ensino-aprendizagem, o Psicólogo Educacional não pode mais compactuar com o antigo paradigma que até então regia toda a nossa prática. Aqui se faz necessário voltar na história e relembrar como nasceu esta especialidade.

Segundo Patto (1997), as primeiras turmas de psicólogos na Universidade de São Paulo tinham a disciplina Psicologia do Escolar e problemas de aprendizagem... numa indicasão clara de que o foco da atensão era o aluno (p. 7). Além disso, conforme a autora, as disciplinas que examinavam os problemas escolares partiam de especialidades como: 
psicologia do desenvolvimento infantil, do excepcional, psicologia diferencial, da aprendizagem, os testes e as medidas, centralizando os problemas de aprendizagem no aluno e concretizando a existência de uma norma, de um padrão de aprendizagem e desenvolvimento considerado normal, adequado e esperado.

Durante muito tempo, permaneceu a idéia de que a prática desse profissional, cujos instrumentos iniciais eram testes para medir a capacidade dos alunos, separando os aptos dos não aptos para a aprendizagem, caracterizando um pensamento excludente, moderno e linear, ou seja, de causa e efeito.

Os testes parecem ter dado lugar à lei do diagnóstico ou laudo: um papel que não explica ao leigo os motivos que levam determinado aluno ao tão famoso "fracasso escolar". Além disso, conforme relata Souza (1997):

a maioria dos psicólogos que emitem laudos psicológicos a respeito das crianças com dificuldades escolares desconhecem a força desse instrumento no meio escolar. Como avaliou Patto, ao estudar casos de multi-repetentes, a avaliação de um profissional de psicologia sela destinos. (p.26)

Utilizando-se de testes ou laudos, sem ética alguma, retirando o aluno da sala para readaptá-lo, para corrigi-lo, todo o fracasso é colocado nos ombros do aluno, que isolado na sua deficiência deve alcançar sucesso por vontade própria, sendo seu destino para sempre selado. É a ordem da moderna ciência da psicologia: excluir para adaptar às categorias universais.

O texto de Soar Filho (1998) apresenta uma reflexão importante acerca de como a ciência moderna e suas categorias universais e válidas para todos as situações e contextos encontram-se atualmente em xeque. Segundo o autor:

não só elas (as categorias) estão sob suspeita, mas o modelo de ciência como um todo, o qual apontava para o ideal da racionalidade, objetividade e neutralidade do conhecimento, e cujo método baseava-se na decomposição dos fenômenos em relações simples de causalidade, na elaboração das leis gerais, na verificação empírica e na replicabilidade dos resultados. (p. 86)

Se seguirmos este pensamento, ou seja, de que um fenômeno isolado é a causa de outro fenômeno, inúmeros argumentos nos servem de explicação para o fracasso do aluno: familia desestruturada, baixa capacidade de concentração, deficiência mental, incapacidade intelectual, carência afetiva, hiperatividade, etc.

Assim, após ter confirmado a máxima do pensamento moderno, segundo o qual as diferenças são fruto das diferenças individuais, não das diferenças de oportunidades sociais- leia-se políticas e educacionais também-, a psicologia educacional firma seu desejo e objeto de estudo: os problemas de aprendizagem das crianças (ver Kupfer, 1997, p. 51).

Seu lugar na escola foi finalmente garantido por uma sala de atendimento dentro da escola, que em nada mudaria o cotidiano escolar se tal atendimento fosse realizado na clínica, fora da escola. A então prática do profissional de psicologia educacional, impregnada do paradigma linear, segundo o qual o aluno é um portador de deficiências, portador de falhas, faltas, não adaptado, enfim, é dono de sua dificuldade, pouco pode fazer em relação ao mesmo a não ser retirá-lo da sala de aula e trabalhar nas suas deficiências fora do contexto de sala de aula.

Segundo Kupfer, no entanto, ao entrar na escola, o psicólogo podia finalmente ater-se às vozes desta, conhecer e sentir o peso dos determinantes sociais sobre os problemas de aprendizagem (Kupfer, 1997 , p. 52) e partilhando destas vozes não poderia continuar com a mesma visão acerca dos problemas de aprendizagem e da sua prática. A escola, porém, continuou com a expectativa criada pela própria psicologia: o profissional de psicologia educacional deve trabalhar com o aluno problema, com o aluno desviante, para que este se adapte às normas, à aprendizagem, enfim, à escola como um todo.

\section{Um outro paradigma}

A famosa "crise da Psicologia", vivenciada por L.S. Vygostky na Rússia do início do século passado, cuja reflexão trouxe frutos para a atual prática pedagógica nas instituições escolares, parece se repetir quando se trata da psicologia educacional, salvaguardando seus limites e perspectivas. Vygotsky (1979, 1983, 1998) elaborou todo um conhecimento acerca de como aprendemos, igualando todos os seres humanos no seu processo de aprendizagem, independente das possíveis limitações orgânicas e/ou físicas. Isso foi um salto qualitativo em termos de como pensamos os seres humanos, tanto que não foi aceito por décadas. Quando antes se pensava o indivíduo por si só, fora de seu contexto social, hoje se torna impossível refletir sobre a escola sem esse olhar de Vygotsky acerca da elaboração social dos processos psíquicos superiores. (ver Seidl de Moura \& Ribas, 2000).

Entretanto, apesar de os achados de Vygotsky e colaboradores darem outro rumo à Psicologia e de darem à instituição escolar uma nova perspectiva de pensamento acerca do processo de ensino e aprendizagem, a Psicologia Educacional de hoje ainda se encontra em crise. Justamente esta especialidade que contempla os processos de aprendizagem e o contexto escolar.

Pode-se citar como fatores desta crise, em primeiro lugar, a demanda que é enorme. Há muitos alunos "desviantes, não adaptados" ao objetivo final da escola: socializar conhecimento científico elaborado historicamente. Em segundo lugar, a visão de muitos dos profissionais da educação ainda está pautada no paradigma de normalidade $\mathrm{X}$ anormalidade, onde se espera um padrão de comportamento e de atitudes que conduzem ao sucesso escolar. Finalmente, não há uma prática elaborada para o trabalho desse especialista no contexto escolar e ela não existe por que não foram elaboradas teorias que reflitam sobre a nossa realidade de escola pública no Brasil, demonstrando a necessidade de uma fazer diferenciado.

Aponta-se aqui para a necessidade de perceber a escola e os problemas ali presentes sob outro paradigma, não mais o modelo da causalidade linear, mas o da causalidade circular, que constitui o pensamento sistêmico baseado na cibernética, na teoria geral dos sistemas e na teoria da comunicação.

Tal pensamento postula a reflexão contextual e a impossibilidade da observação neutra e seus princípios são os seguintes: totalidade (o 
todo é maior que a soma das partes, ou seja, o funcionamento do sistema não pode ser entendido a partir do funcionamento de um só indivíduo); integridade de subsistemas (os sistemas possuem subsistemas que são integrados, relacionados uns aos outros); circularidade (todos os componentes influenciam-se mutuamente) (ver Schaffer, 1996, p. 205).

Para Tilmans-Ostyn e Kinoo (s/d):

O pensamento sistêmico funciona segundo um modelo circular. Isto significa que o lugar, o momento no qual situamos o inicio de um processo interacional, para daí deduzir uma compreensão, é totalmente arbitrário. Para iniciar a compreensão de tal processo, podemos ver outras coisas. A questão de saber quem começou, quem é a causa, não tem portanto sentido neste modo de pensamento. (p. 3)

Dessa forma, para compreendermos o processo interacional é preciso considerar diversas causas, assim como a função que determinado problema está exercendo neste processo. Tilmasn-Ostyn e Kinoo (s/d), ao avaliar o processo relacional familiar, segue afirmando que:

... o enfoque sistêmico tanto na investigação como no trabalho clínico têm mostrado como o sintoma apresentado pelo paciente identificado é uma solução para manter a unidade e o equilíbrio funcional familiar neste momento determinado. Isto significa que num primeiro momento o objetivo do médico não será necessariamente a superação do sintoma, mas de buscar o sentido positivo que este sintoma pode ter para a família (p. 3).

Com esta revolução no pensamento, o aluno não pode mais ser visto como sujeito dotado de problemas, como um ente separado do sistema relacional (família e escola), mas como um sujeito relacional. O Psicólogo Educacional não mais possui hipóteses "verdadeiras" sobre os problemas do aluno, tampouco se faz neutro na escola e nas relações que ali estabelece, pois sua simples presença já modifica o sistema observado (ver Soar Filho, 1998, p. 88). Além disso, precisa aceitar a idéia de que uma dificuldade de aprendizagem pode estar exercendo alguma função em um dos sistemas no qual o aluno vive.

Assim, o Psicólogo Educacional que se baseia no novo paradigma já não pode mais eleger um único modelo de explicação para as dificuldades de aprendizagem, como, por exemplo, o modelo organicista, pois precisa considerar múltiplas versões de um mesmo fenômeno (sem que apenas uma seja a mais verdadeira) e trabalha na interdisciplinaridade.

É importante lembrar, porém, como relata Soar Filho (1998) que os modelos de causalidade linear ou simples não são descartados, mas compreendidos como partes de modelos de complexidade crescente (p. 86). Assim, não se trata de abandonar o modelo de pensamento que nos serviu como base até então, mas de incorporá-lo ao modelo sistêmico.

\section{Uma outra prática}

Entre as tarefas descritas pelo CFP na resolução no 014/00, mencionada anteriormente, destaco as seguintes possibilidades de atuação do psicólogo educacional: a) aplicar conhecimentos psicológicos na escola, concernentes ao processo ensino-aprendizagem, em análises e intervenções psicopedagógicas; referentes ao desenvolvimento humano, às relações interpessoais e à integração família-comunidadeescola, para promover o desenvolvimento integral do ser;

b) analisar as relações entre os diversos segmentos do sistema de ensino e sua repercussão no processo de ensino para auxiliar na elaboração de procedimentos educacionais capazes de atender às necessidades individuais.

Inúmeras perguntas surgem a partir de uma leitura contextualizada e histórica da prática do Psicólogo Educacional e a partir das tarefas acima mencionadas. Tais perguntas podem ser acrescidas das seguintes: como promover o desenvolvimento integral do ser? Quais as intervenções psicopedagógicas mais adequadas? Como integrar a famillia no processo de aprendizagem? Como atender às necessidades individuais dos alunos no atual sistema educacional? Enfim, parece que a crise atual da psicologia educacional se encontra na impossibilidade de responder tais perguntas a partir do paradigma que até então regia nossa prática.

Para diferenciar-se, portanto, o Psicólogo Educacional que adentra uma instituição escolar, consciente do momento histórico de sua especialidade, precisa de início mostrar uma outra postura. Uma reunião inicial com a equipe pedagógica (orientadores e supervisores e direção, assim como professores) é mais que necessária, não só para colher dados concretos acerca da escola, mas principalmente para demonstrar que visão de sujeito o psicólogo tem, o que pensa acerca dos problemas de aprendizagem, que estratégias diferenciadas tem a oferecer além do esperado atendimento individual na sala do psicólogo.

Da mesma forma, o Psicólogo Educacional precisa criar um espaço para escutar as demandas da escola e pensar maneiras de lidar com situações que são cotidianas. Precisa criar formas de reflexão dentro da escola, com todos os sujeitos (alunos, professores e especialistas) para que se possa trabalhar com suas relações e paradigmas.

Ele precisa ouvir os alunos, o que pensam sobre sua escola e sua turma. Isso pode ser feito através de desenhos ou pedindo para que escrevam o que pensam, sentem, como percebem sua turma e sua escola. É igualmente necessário ouvir os professores, suas demandas e fazê-los participar dos atendimentos com as crianças, repensando novas práticas e novos olhares sobre o aluno que chama de "problema". Assim, o psicólogo educacional não cairá em armadilhas do tipo não sei mais o que fažr, dê conta desse problema para mim.

Também se faz necessário trabalhar junto à equipe pedagógica, criando espaços semanais de diálogo com os professores para que juntos cheguem a novas versões de um mesmo fenômeno, eliminando a possibilidade de estigmatizar os alunos com dificuldades.

Enfim, chamar a família do aluno com dificuldades a fim de que se possa colher dados acerca do outro sistema direto em que participa o aluno. Junto com a família, refletir sobre a função 
desta dificuldade neste momento do ciclo vital da família e criar estratégias para possibilitar o sucesso da criança. Confrontar família e professor quando necessário, criando um espaço de dialogo franco acerca das dificuldades de todos, não só do aluno, diluindo nos sistemas a "culpa" pelo fracasso escolar. Assim, outra armadilha é enfraquecida: a culpa sempre é da família.

A participação do Psicólogo Educacional está no cotidiano da escola, nas reuniões de conselho de classe, onde poderá estabelecer novas maneiras de olhar os alunos, evitando rótulos, diagnósticos imprecisos e hipóteses únicas. Deverá também participar do processo de construção do Projeto Político Pedagógico da escola.

Estudar e investigar o histórico escolar deste aluno indesejado ajuda muito, às vezes sua história de fracasso escolar é proveniente de outras instituições e pode ser revertido se toda a equipe de profissionais se reconhecer como agente de transformação social. O Psicólogo Educacional, questionador, curioso e acima de tudo assumindo uma posição de "não saber", pode criar junto à equipe uma estratégia de intervenção colaborativa, onde todos têm influência sobre o aluno, assim como sofrem influência mutuamente.

Finalmente, precisa ter a cautela para diferenciar problemas e para que as soluções sejam as mais justas e eficazes, ou seja, se um aluno é portador de necessidade especial, certamente um olhar organicista poderá ajudar na criação de estratégias de intervenção. $\mathrm{O}$ que aqui desejo afirmar é que não se pode descartar a possibilidade de existência de problemas de ordem congênita ou familiar, mas não justificar todo e qualquer comportamento inesperado de um aluno como fator de desajuste do próprio aluno.

\section{Referências}

Kupfer, M. C. M. (1997). O que toca a/à Psicologia Escolar. Em A. M. Machado \& M. P. R. Souza (Orgs.), Psicologia escolar: Em busca de novos rumos (3ª ed.). São Paulo: Casa do Psicólogo.

Patto, M. H. S. (1997). Prefácio de psicologia escolar: Em busca de novos rumos ( $3^{\mathrm{a}} \mathrm{ed}$.). São Paulo: Casa do Psicólogo.

Seidl de Moura, M. L. \& Ribas, A. F. P. (2000). Desenvolvimento e contexto sociocultural: A gênese da atividade mediada nas interações iniciais mãe-bebê. Psicologia: Reflexão e Crítica, 13, .

Souza, M. P. R. (1997). A queixa escolar e o predomínio de uma visão de mundo. Em A. M. Machado \& M. P. R. Souza (Orgs.), Psicologia escolar: Em busca de novos rumos ( $3^{\mathrm{a}}$ ed.). São Paulo: Casa do Psicólogo.

Soar $\mathrm{F}^{\circ}$, E. J. (1998). Novos paradigmas da psicologia e das terapias psicológicas pós-modernas. Psicologia: Teoria e Pesquisa, 14,.

Tilmans-Ostyn, E. \& Kinoo (s/d). Algunos aportes de la terapia familiar a la práctica médica cotidiana. Hospital: Herminio Valdizan. Departamento de Psiquiatria Familiar.

Vygotsky, L. S. (1983). Obras escojidas (Vol. III). Moscú: Aprendizaje Visor.

Vygotsky, L. S. (1998). A formação social da mente (6a ed.). São Paulo: Martins Fontes.

Vygotsky, L. S. (1979). Historia del desarollo de las funciones psíquicas superiores. La Habana/Cuba: Científico-Técnica.
Recebido: 04/03/2004

Aceite final: $14 / 04 / 2004$

Sobre a autora

Edla Grisard Caldeira de Andrada é Graduada em Letras e em Psicologia pela Universidade Federal de Santa Catarina. É Mestre e Doutoranda em Psicologia pela mesma instituição. É Psicóloga da Secretaria Municipal de Educação de São José/SC. 